\title{
Organização espacial das redes de transportes e comunicações na América do Sul: uma análise baseada nas revoluções logísticas
}

Vitor Hélio Pereira de Souza

Universidade Federal de Santa Catarina, Brasil.

\author{
Márcio Rogério Silveira \\ Universidade Federal de Santa Catarina, Brasil.
}

Recebido: 18 de diciembre de 2018. Aceptado: 7 de junio de 2019.

\section{Resumo}

Na América do Sul persiste um padrão de inserção periférica ao mercado mundial. É evidente que isso não ocorre somente nas transações econômicas, mas também acontece como estrutura de um padrão de ocupação do território que formou importantes redes técnicas de transportes e comunicação. Tais redes percorrem as fachadas atlânticas e litorâneas, bem como os corredores de exportação entre o interior, produtor de matérias-primas, e os portos-empórios, no litoral (sejam voltados para o Atlântico ou para o Pacífico). Nesse contexto, o artigo objetiva analisar a evolução e organização das redes técnicas de transportes e comunicações da América do Sul, por meio da estrutura, do processo, da função e das formas permeadas no território por meio da metodização das revoluções logísticas.

\section{South America means of transport and communication network spatial organization: an analysis based on logistic revolutions}

\footnotetext{
Abstract

In South America a pattern of subordinated insertion to the world global market persists. It is well known that this does not occur only in economic transactions but also as a structure of a territory occupation pattern that has created important technical networks of transport and communication. Those networks cover the Atlantic and coastal forefronts as well as the hall of exportation between the interior, producers of raw material, and the emporiums, at the seaside (being turned to the Atlantic or the Pacific). In this context, this article aims to analyze the evolution and the organization of technical network means of transport and communication throughout South America, through structure, process, function and the permeated in the territory through the methodology of logistic revolutions.
}

Palavras-chave

América do Sul Redes de transporte Organização espacial Revoluções logísticas

Palabras clave

Sudamérica Redes de transporte Organización espacial Revoluciones logísticas

\section{Keywords}

Sudamérica Networks Transport Spatial organization Logistic revolutions 


\section{Introdução}

As investigações geográficas com temáticas sobre circulação, transportes e logística, que utilizaram como recorte espacial a América do Sul, representam uma produção acadêmica reduzida. Uma investigação, em que se adota uma escala geográfica e temporal mais ampla, expõe-se ao risco da análise apresentar características mais generalistas, uma vez que não é possível salientar as particularidades decorrentes das diferentes formações econômicas e sociais nacionais sul-americanas, assim como as diversas dinâmicas territoriais existentes.

Ainda assim, devemos considerar que há uma formação histórica comum aos países sul-americanos resultante das desiguais correlações da região com o centro do sistema capitalista mundial. Esse fator influiu (e influi) diretamente na organização do espaço geográfico, definida especialmente pelas redes de transportes e comunicações que, por sua vez, foram edificadas para o estabelecimento de relações comerciais e de poder com as metrópoles: Portugal e Espanha.

Em outras palavras, a história das redes é inerente à história dos territórios de onde elas estão situadas, bem como dos diferentes e conjugados modos de produção (Rangel, 1993) a que serviram e das técnicas disponíveis (Raffestin, 1993). Nesse sentido, o artigo objetiva mostrar a produção/reprodução e organização/reorganização das redes de transportes e comunicações latino-americana.

Para tanto, adotamos no artigo uma periodização pautada na metodização das "revoluções logísticas"1 (Silveira, 2009), que apresentam um aporte para a compreensão dos contextos em que foram gestadas as inovações técnicas e organizacionais no setor de transportes, armazenamento e logística, e como as mesmas difundiram-se mundialmente, modernizando as infraestruturas e meios de transportes e consequentemente as lógicas políticas, sociais e econômicas, que influem nos territórios.

Nessa perspectiva, a logística ${ }^{2}$ perpassa todos os modos de produção ou qualquer fase deles, tratando-se de uma condição fundamental para as modernizações dos sistemas técnicos de transportes (dos mais primitivos aos mais modernos), que ocorre de maneira desigual e combinada nos espaços sul-americanos. Resultando na seleção da ampliação da fluidez de determinadas porções do território, em detrimento de outras, isto é, aumentando a velocidade, otimizando as rotas e reduzindo o tempo de circulação, alterando assim a relação espaço/tempo.

A velocidade, na realização da circulação, é um componente, muitas vezes, menosprezado na organização dos territórios, especificamente quando tratamos das relações sociais que o seu uso seletivo permite intensificar ou neutralizar. Uma vez que, essas relações sociais estão cada vez mais coligadas às lógicas capitalistas de circulação do capital (produção, distribuição, troca e consumo).

Nesse sentido, ao experimentar a aceleração contemporânea,

(...) outra vez, nos tornarmos, como na aceleração precedente, adoradores, dubitativos ou firmes, da velocidade. Esta última espantou os que viram surgir a estrada de ferro e o navio a vapor e, depois, viveram o fim do século 19 e o já longínquo começo do século 20, com a invenção e a difusão do automóvel, do avião, do telégrafo sem fio e do cabo submarino, do telefone e do rádio (Santos, 1994:12).

Justamente, com o propósito de evidenciar alguns dos importantes períodos de estruturação e modernizações das redes de transportes e dos territórios sul-americanos,

1. O conceito de revoluções logísticas foi proposto inicialmente por Anderson (1990) em seu artigo Les quatre révolutions logistiques, e criticada e requalificada por Silveira (2009) enquanto revoluções e evoluções logísticas, com alterações significativas nas suas estruturas, processos, funções e formas. 2. A logística, lato sensu, é compreendida enquanto estratégia, planejamento e gestão da circulação (transporte e armazenamento) de mercadorias, capitais e pessoas, que pode ser utilizada por diversos agentes: indivíduos, corporações e Estado (Silveira, 2009). 
advindos das modernizações do centro do sistema capitalista, esse manuscrito foi disposto, além da introdução e considerações finais, nos seguintes tópicos:

» Da sedentarização do homem às trocas comerciais;

" A criação de vias de penetração e espoliação na América do Sul;

» A modernização das vias de penetração e espoliação na América do Sul fortalece o sistema mercantil;

" A criação do mercado doméstico e a integração dos territórios nacionais;

" A América do Sul, um continente em modernização e com padrões secularmente persistentes.

A abordagem dos aspectos elencados em cada um desses tópicos proporciona elementos para analisarmos apropriadas particularidades da gênese, expansão e modernização das redes de transportes e comunicações sul-americanas. Tais infraestruturas foram espacializadas e manifestadas em formas, cuja função é manter/potencializar as relações de produção vigente, ora preservando algumas estruturas espaciais assumidas em outro espaço/tempo e, ora destruindo outras, com propósito de assegurar uma certa intensidade nos padrões de acumulação capitalista.

\section{Da sedentarização do homem às trocas comerciais}

Foi com a sedentarização do homem que cada sociedade passou a aparelhar seu espaço de vida, enquanto que as técnicas inventadas e aperfeiçoadas serviram para garantir sua subsistência. Desse modo, as "combinações geográficas", conjunto de condições físicas presentes em cada espaço, atreladas às técnicas disponíveis no presente tempo (Cholley, 1964), possibilitaram a cada grupo elaborar uma organização espacial peculiar da produção e da divisão do trabalho.

$\mathrm{O}$ ato de transportar e armazenar e, destacadamente, o de planejar e de gerir a circulação passou de um estágio simples (nomadismo) para relações cada vez mais complexas (sedentarização e formação de redes urbanas). Essas relações são intrínsecas à própria produção e à reprodução dos grupos humanos. E os modos de transportar e armazenar, além das tecnologias que os viabilizaram, chocaram-se com o que existia de mais moderno no mundo. Nesse contexto, velocidades e temporalidades diferentes entraram em contradição e em constantes interações (Silveira, 2011). Portanto, interações espaciais entre diferentes espaços e com díspares níveis de modernizações contribuíram para uma reorganização desigual de diversos espaços, e a América do Sul padeceu desses episódios.

Com a geração de excedentes deu-se o início das relações de trocas entre diversos grupos humanos por meio do escambo de produtos, como: sal, peles, gado, metais, e mais tarde, a moeda. No decorrer da história, essas trocas se tornaram mais frequentes, passando a ocorrer também entre povos (localizados) mais distantes, o que implicou na necessidade de reduzir o tempo de circulação das mercadorias. Tempos lentos e rápidos foram ajustando-se continuamente, permitindo a complementaridade entre diferentes localidades, cujas modernizações ocorreram de forma mais homogênea, e consequentemente, com menores impactos socioespaciais.

Tal situação impôs a busca de técnicas aplicadas aos sistemas de transportes e comunicação, que ocasionaram revoluções logísticas de grande importância para o desenvolvimento da organização do trabalho, visto que o transporte trata-se de uma "condição geral de produção", requisito imprescindível para assegurar a capacidade de produção das diversas localidades, uma vez que a instalação das redes modificam os valores dos objetos no espaço, além do próprio espaço através de modificações na renda da terra (Marx, 2005). 
Consequentemente, essas transformações possibilitaram a elevação dos fluxos entre distintos espaços, em outras palavras as "interações espaciais", entendidas não somente como simples deslocamento no espaço (Haggett, 1965; Ullman, 1972; Corrêa, 1995), mas, também, enquanto parte integrante da produção do mesmo, que possuem a propriedade de atenuar ou intensificar processos pré-estabelecidos, assim como de transformá-los (Silveira e Cocco, 2010), que ocorre de modo particular em cada fase histórica do desenvolvimento das forças produtivas e das relações de produção.

As revoluções dos meios de transportes e comunicações afetaram as relações sociais, e a velocidade dessas interações socioespaciais cresceu geometricamente, apesar de existirem algumas descontinuidades históricas e espaciais. Ora, se o capital é uma relação social (Marx, 2005), as modificações das infraestruturas de transporte e comunicação influem em alterações nas relações sociais pré-estabelecidas, assim como na produção/ reprodução e na organização/reorganização do espaço geográfico.

A frequência dessas relações de trocas entre os diversos grupos humanos repercutiu numa série de revoluções logísticas. Esses eventos foram gestados na Mesopotâmia, Egito, Grécia, Roma, com destaque para as caravanas que utilizavam a tração animal e a tração animal combinada ao uso da roda (Silveira, 2009). Essas técnicas aplicadas, embora pareça banal nos dias atuais, possibilitou o estabelecimento de rotas comerciais terrestres que se configuraram em estradas que, por sua vez, "(...) imprime-se no solo; semeia germes de vida: casas, lugarejos, aldeias, cidades” (La Blache, 1923:293).

Ademais, o uso dessa infraestrutura resultou na criação de uma rede urbana de cidades manufatureiras e comerciais, composta por um lugar central e espaços hierarquizados, ${ }^{3}$ como foi o caso da rede de cidades da Liga Hanseática (aliança de cidades mercantis de influência alemã, que monopolizou o comércio sobre quase todo norte da Europa e, inclusive a região dos países Bálticos, em fins da Idade Média e começo da Idade Moderna) e das cidades italianas de Toscana, Genova e Veneza (Silveira, 2009).

A prosperidade do comércio sob controle do Império Romano cessou com as invasões germânicas (bárbaras). A decadência desse modo de produzir a vida social propiciou o florescimento do sistema feudal e o declínio de um avançado sistema de trocas repleto de um intricado sistema de transportes e logística. A despeito dessa inflexão nas relações comerciais e, por isso, também nas técnicas e organizações de transportes e armazenamento sob o domínio do Império Romano do Ocidente, outros espaços continuaram florescendo, formando redes urbanas, tanto por vias terrestres como por rotas marítimas, controladas por árabes, indianos e chineses. É justamente nesse período que outra revolução logística ocorre na China e Índia entre o final do século VII e primeira metade do século XIX.

Foi somente a partir do século XII - com: 1) a geração de excedentes no interior do sistema feudal (quando as relações de renda-dinheiro suplantou as de renda-trabalho e de renda-produto); 2) as diferenciações sociais entre os antigos servos; 3 ) o comércio com o Oriente Médio devido às incursões das Cruzadas; 4) a formação das corporações de ofícios nas cidades, e em seguida, as manufaturas; e 5) a criação de grandes cidades - que as trocas comerciais se tornaram o fator dominante das novas relações de poder mercantis na Europa (Dobb, 1983).

Nesse novo período, inicia-se a gestão de uma revolução logística na Europa que, por conseguinte, teve nas expansões marítimas seu ponto mais relevante. Sucedeu-se uma maior intensificação das transações comerciais e restabeleceram-se relações de trocas perdidas. Estas, por sua vez, surgiram com características ainda mais complexas, fruto dos avanços técnicos e organizacionais das redes de transportes, que abarcaram notadamente partes dos territórios correspondentes ao antigo Império Romano do Ocidente,
3. A Teoria das Localidades Centrais, de Walter Christaller (1966), ajuda a entender tal processo, pois ela aponta para o limite e a distância (threshold e range) como leis que governam o número, o tamanho e distribuição dos lugares (cidades). 
fragmentado em diversas cidades-estados. Essa dinâmica propiciou a reabertura das rotas comerciais terrestres e o estabelecimento de rotas ultramarinas, permitindo aos estados nacionais europeus, ainda em composição, conquistas coloniais. Criaram-se as bases para uma nova revolução logística.

\section{A criação de vias de penetração e espoliação na América do Sul}

O renascimento do comércio europeu, entre os séculos XII e XVI, redundou numa revolução logística. Fato que levou a recuperação territorial e comercial (baseada na ideologia da reconquista, movida a todo custo pelos países ibéricos) das antigas rotas de trocas, a criação de instituições bancárias e uma ideologia amplamente mercantil (Silveira, 2009). Tais fatores contribuíram para consolidação da historia da supremacia econômica do Ocidente, ${ }^{4}$ por meio da concorrência aos árabes, indianos e chineses, até então em vantagem no comércio marítimo, além de proporcionar as bases para a expansão marítima colonial (Clydesdale, 2012).

O forte ressurgimento das atividades mercantis foi responsável pelo processo de unificação da técnica e do "gênero humano" ao situar a Terra como nova escala para a reprodução social, consolidando o "mercado mundial" (Marx, 1978). E, sob a perspectiva do colonizador (europeu), estabeleceu-se a história universal, sendo que essa “(...) não existiu sempre: a história como história universal é um resultado” (Losurdo, 2006:22).

Nesse contexto, a história da conquista do "Novo Mundo", no decorrer do século XV por Espanha e Portugal, tornou-se parte da trajetória do desenvolvimento do capitalismo europeu, sendo resultante da busca por rotas alternativas para o Oriente e para África Subsaariana. A finalidade foi à obtenção de mais lucro para o comércio de produtos, como: seda, porcelana, cravo, canela, pimenta, noz-moscada, entre outros (Silveira, 2009).

A implicação foi, aos poucos, o triunfo da hegemonia europeia, mediante a alternância de hegemonia entre as nações, e da supremacia da "civilização ocidental" sobre os demais povos. Pela primeira vez na história a hegemonia que se estabelecia com os europeus era mais ampla espacialmente que as das nações anteriores. Todavia, essa hegemonia só foi consolidada após um longo período de "acumulação primitiva de capital" que, em consequência, financiou o nascimento da grande indústria moderna, fundando as bases da relação centro-periferia (Mamigonian, 2000).

A espoliação das Américas foi possível pela existência de discrepantes temporalidades técnicas e de velocidades que se chocaram, se acomodaram e que ainda são conflituosas. A modernização que alcançou as Américas foi seletiva, desigual e combinada, abrangendo relações primitivas de produção pré-existentes a uma lógica capitalista, feudal e escravista (Rangel, 1985). Nelas, as relações de produção e trabalho mais modernas e atrasadas, vigentes na Europa (mercantilismo para fora e, em alguns casos, feudalismo internamente em decadência), relacionaram-se diferentemente com diversas formas de produção da vida material e espiritual nos territórios do continente Americano (Rangel, 1993).

Formas e funções primitivas de transportes e de logística do "novo mundo" entraram em conflito com as do "velho mundo", e decorrente dos avanços e retrocessos, surgiram formas hibridas, portanto, o primitivo incorporou o moderno, da mesma forma que o moderno unificou as formas primitivas de circulação e de interações espaciais. Prontamente, ao longo de mais de cinco séculos a América latina foi marcada por encontros abruptos, cujo saldo foi à desigualdade entre os territórios e suas formas de circulação, de interações espaciais e o que resulta delas, ou seja,
4. No fim do século XIII, Marco Polo quando chegou à China estava na presença da nação mais rica do mundo; no século XV, Vasco da Gama ao chegar à Índia, notou que seus produtos não impressionavam, tendo que comercializar utilizando ouro, ao invés de mercadorias (Clydesdale, 2012). Os chineses e os guzerates (Índia) até a difusão do barco a vapor continuaram dominando a navegação nos oceanos do Oriente em volume e valor de cargas transportadas, sendo a supremacia econômica do Ocidente um fenômeno relativamente recente (Clydesdale, 2012). 
uma produção do espaço expressivamente desigual (Novack, 1968). Produção que permitiu formações socioespaciais (Santos, 1982) em diferentes estágios de desenvolvimento econômico e social.

O papel da América Latina tornou-se o de prover riquezas para a metrópole, seja pela exploração de minérios preciosos nas colônias hispânicas, seja pela agricultura tropical (cana-de-açúcar) nas colônias portuguesas, uma vez que nestas não seriam encontrados metais preciosos nos primeiros dois séculos de colonização (Furtado, 1986). Dinâmica que redundou na manutenção de vazios produtivos e na admissão nas colônias de relações de produção e trabalho já suplantados ou em desmantelamento na Europa (Rangel, 2005).

Tal função, atrelada às características físicas do território sul-americano, com destaque para a geomorfologia do continente, daria origem a

Uma rede continental inicial, quase sempre comandada pelo ponto de partida dos descobridores, que ao mesmo tempo é um ponto de chegada dos fluxos de bens; uma rede marítima com rotas comandadas pelos ventos e pelas correntes marítimas, e uma rede continental embrionária nas terras recentemente descobertas (Raffestin, 1993:214).

As primeiras incursões colonizadoras na América Hispânica, ainda que a Cordilheira dos Andes fosse uma barreira geomorfológica difícil de vencer, ocorreram por rotas terrestres, muitas vezes já existentes, resultantes da descoberta de metais preciosos nos primeiros contatos dos colonizadores com os autóctones (Shanahan, 1954). Ademais, a presença de sistemas de governo mais ou menos aparelhados contribuiu para que, uma vez derrubado o poder central, rapidamente fossem conquistados, até o final da segunda metade do século XVI, a maior parte dos vastos territórios (e suas redes), sobre o controle dos antigos povos (Pendle, 1963).

Na América Portuguesa não houve descoberta de metais preciosos nos primeiros séculos de colonização. Entre a fachada Atlântica e o planalto paulista a Serra do Mar apresentava-se enquanto obstáculo para exploração, mas a rede hidrográfica existente facilitou o desbravamento, contribuindo para que as incursões ocorressem primeiramente por meio de rotas fluviais navegáveis, e somente em um segundo momento, por vias terrestres (Shanahan, 1954; Santos, 1982).

Nesse sentido, as primeiras investidas ocorreram pelos rios, na região do vale do Paraíba e possibilitaram acesso ao planalto de São Paulo, e consecutivamente, ao vale do Tietê, a partir de onde alcançaram os estados do Paraná e do Mato Grosso; já pelo vale do São Francisco foi possível chegar ao estado de Minas Gerais; e partindo do Maranhão, pelo rio Amazonas, apossaram-se de Manaus (Corrêa, 2006).

As "combinações geográficas" (Cholley, 1964) da área, com seus aspectos físicos (relevo, hidrografia, clima) e biológicos (solo e vegetação), juntamente com as técnicas disponíveis (aspectos humanos), influíram na consolidação das primeiras vias de penetração, para a espoliação recorrente do território, em outras palavras, nos caminhos abertos para conquista e exploração das Américas e na sua feroz ocupação.

Na América do Sul, em grande medida, esses mesmos caminhos, ainda presentes contemporaneamente, modernizados ou não, foram edificados sobre passagens primitivas ou seguiram as margens (planícies de inundações) dos principais rios de penetração e comunicação (Silveira, 2011). Muitos pontos de paragens (caminhos das tropas e das bandeiras capturadoras de homens e de gados), de exploração (minérios) e de ocupação originaram as primeiras vilas e cidades sul-americanas. Algumas surgiam 
já em sua gênese atreladas ao comércio internacional (produção/exploração-porto/ empório), e outras surgiram para manutenção do território e para acolhimento do mercado interno em desenvolvimento (Pendle, 1963; Shanahan, 1954; Santos, 1982; Furtado, 1986; Raffestin, 1993).

Contudo, devemos salientar que o continente Sul Americano, experienciou uma ocupação particular na América hispânica e lusa, devido sua geografia física, sua forma de exploração, a resistência dos povos originários (em diferentes estágios de desenvolvimento) e as diversas nuances das combinações geográficas. Como relata Ignácio Rangel (1993), a parte sob domínio da Espanha originou "nações", mais ou menos homogêneas, condizentes com suas concernentes geografias físicas, à medida que, na porção portuguesa, a menor heterogeneidade, sob a perspectiva da geografia física, deu origem, não a várias unidades políticas, mas a uma só futura nação de dimensões continentais.

Na América hispânica, os colonizadores utilizaram-se, muitas vezes, das infraestruturas mais "modernas" e com maior capacidade de fluxos construída pelo Império Inca (para uso do governo e do exército da época). Tratava-se de uma extensa rede de transportes, composta por caminhos, que serviam para viabilizar as comunicações de uma considerável rede urbana.

\section{(...) Tendo ao todo talvez 16.000 mil quilômetros de calçamento, esse vasto sistema rodoviário consistia em duas artérias principais correndo no sentido norte-sul, uma acompanhando a costa e a outra, o franco leste dos Andes, cada qual com 3.200 quilômetros, comunicando-se entre si através de várias vias de ligação no sentido leste-oeste (Helferich, 2005:273).}

Segundo Keeling (1993), a utilização das infraestruturas dos povos colonizados é evidente, também, nas primeiras estradas criadas no noroeste argentino, entre outros espaços. Na América hispânica, devido a localização das jazidas de minério ser mais ao interior do continente, e por ser um produto final de elevado valor e peso, ele carecia de grande vigilância do fisco (Santos, 1982). Sendo assim, a atividade mineradora induziu o desenvolvimento de diversos sítios urbanos, ${ }^{5}$ utilizados enquanto pouso para os tropeiros que transportavam minerais, esse foi o caso de cidades, como: La Paz (na época chamada de Chuquabo), Juliaca, Puno, Juli e Copacabana (Sánchez, 1969). O mesmo ocorreu mais tarde no Brasil, a partir do século XVII, com a formação de uma rede de cidades no interior do Brasil.

Tais fatores, entre outros, influíram para que grande parte das primeiras cidades na fachada do Pacífico se desenvolvesse mais ao interior do território, algumas sobre centros urbanos pré-colombianos, como foi o caso de Cuzco e da Cidade do México. Ademais, nos primeiros anos ocorreram dificuldades para instalação de cidades no litoral devido ao terreno mais acidentado da área, resultando na criação de portos subsidiários que não apresentaram, a princípio, desenvolvimento urbano autônomo (Santos, 1982).

Na porção lusa do continente, com um vasto território, com aspectos naturais menos heterogêneos que na América espanhola, a fachada Atlântica com o relevo menos acidentado e o solo de boa qualidade (nos vales de muitos rios) foram convenientes para o desenvolvimento de diversas colônias que, por conseguinte, originaram pequenas produções mercantis (Rangel, 1993).

Em partes do planalto brasileiro, por outro lado, formaram-se grandes latifúndios pautados na produção tropical (canavieira, pecuária bovina e cafeicultura), que resultaram em um produto de elevado peso e expressivo valor, ainda que não equiparável
5. As primeiras cidades fundadas não apresentavam um grande número de moradores. Na América Hispânica, a lei indicaria mais tarde que bastavam dez chefes de família para se fundar uma cidade. Já para escolha da futura localização da cidade, além da proximidade das minas de ouro e prata, eram considerados diversos fatores, como: a segurança; o apoio da população autóctone; a salubridade; a fertilidade do solo; além da presença dos materiais necessários para a construção das futuras cidades (Dominguez Compañy, 1978). 
ao minério. Este, ao manter sua localização próxima ao litoral, adquiriu uma redução considerável no seu custo de transporte, fato que culminou no desenvolvimento de cidades portuárias (porto-empório) de grande importância (Santos, 1982).

Uma vez que as colônias apresentavam economias competidoras (matéria-prima), a única complementaridade que havia entre as mesmas ocorria com a metrópole (produtos elaborados), transcursando na momentânea inexistência de comércio entre os países da região (Furtado, 1986). Também é pertinente a descrição de Darcy Ribeiro (1997):

Efetivamente, a unidade geográfica jamais funcionou aqui como fator de unificação porque as distintas implantações coloniais das quais nasceram as sociedades latino-americanas coexistira sem conviver, ao longo dos séculos (Ribeiro, 1997:23).

Assim, estabeleceu-se uma organização espacial decorrente do comércio mercantil com a Europa, definido por arquipélagos geoeconômicos com conexões mais fortes com a metrópole/centro do sistema econômico mundial do que com outras partes do mesmo território. Tal lógica contribuiu para um processo de ocupação e de urbanização diversificado do europeu.

Não houve, nos países subdesenvolvidos, como aconteceu nos países industriais, uma passagem da população do setor primário para o secundário e, em seguida, para o terciário. A urbanização se fez de maneira diferente e tem um conteúdo também diferente: é uma urbanização terciária. Somente depois, evidentemente com exceções, é que a grande cidade provoca a criação de indústrias (Santos, 1971 apud Grimm, 2010:172).

De acordo com Beyer (1969:81), na América do Sul, “(...) as cidades não florescem no campo, mas foram, pelo contrário, plantadas nele". O desenvolvimento econômico, bem como a consolidação da urbanização e das redes de transportes, ocorreu de forma inorgânica e desarticulada, voltada ao exterior. A direção das redes e dos fluxos era para o interior/produção-litoral/portos, e nas vastas porções do território da América do Sul, formaram-se diversos bolsões econômico-populacionais mais conectados ao centro hegemônico do que entre si (Silveira, 2007).

Nesse sentido, as características geomorfológicas da América Hispânica, a criação de oligarquias regionais, o isolamento entre as regiões geoeconômicas, entre outras (múltiplas) determinantes, atreladas a baixa integração interna contribuíram após a independência para a fragmentação do território da América espanhola em diversas nações, grosso modo, homogêneas territorialmente (Rangel, 1993). Pendle (1963:96), recorda que muitos estudiosos ponderaram que “(...) se a emancipação da América espanhola se arrastasse por uns cinquenta anos, teriam sido construídos caminhos de ferro e desse modo seria evitada aquela fragmentação nacional".

Porém, na América lusa, ainda que o território, também, estivesse pouco integrado, a menor heterogeneidade dos aspectos naturais, a gestão portuguesa do território (rotatividade dos funcionários do Estado pelas capitanias e pelas províncias) e a capacidade de reprimir levantes independentistas e separatistas contribuíram para que, apesar de alguns percalços, mesmo após a independência, surgisse uma nação de dimensões continentais e com problemas singulares, decorrentes de sua grande extensão territorial, o Brasil (Rangel, 1993).

De fato, na América espanhola e portuguesa a distribuição das redes de transportes e comunicações, orientadas para a metrópole, resultou em uma tardia integração interna dos territórios das nações recém-emancipadas. E, consecutivamente, uma mais tardia 
busca de integração infraestrutural entre as nações (supranacional). Tal condição perduraria por séculos, com estradas precárias que dificultavam a viagem entre os núcleos urbanos das colônias. O geógrafo e naturalista prussiano, Alexander von Humboldt, em 1799, desembarcou na Venezuela; passou por Cumaná, o mais antigo assentamento europeu contínuo na América do Sul, fundado em 1523, e seguiu em direção às terras altas habitadas pelos índios Chaymas, trajeto que levou o mesmo a relatar na época:

Sem vizinhos, quase desligados do resto da humanidade, cada família de colonos forma uma tribo separada. Esse isolamento detém ou retarda o progresso da civilização, que só avança à medida que as sociedades se multiplicam e suas ligações ficam mais íntimas e espalhadas. Mas, por outro lado, é a solidão que desenvolve e fortalece no homem o sentimento de liberdade e de independência; e dá origem àquele temperamento nobre e orgulhoso que sempre distingui a raça castelhana (Humboldt apud Helferich, 2005:88).

\section{A modernização das vias de penetração e espoliação na América do Sul fortalece o sistema mercantil}

A revolução logística, gestada com mais veemência na Inglaterra, no início do século XVIII e parte do século XIX (Silveira, 2009), sustentou a Primeira Revolução Industrial (meio técnico) na conjuntura de uma nova ordem internacional (Derruau, 1969). Antes disso, a Revolução Francesa (1789) retirou de foco os valores absolutistas em detrimento de ideais burgueses. Esse evento histórico, ao atingir as principais monarquias europeias, apressou o colapso do regime feudal, e consecutivamente, a emergência da Primeira Revolução Industrial na Inglaterra (Derruau, 1969; Furtado, 1986). Fato que permitiu a expansão mais veemente do capitalismo e que, mais tarde, consolida a hegemonia inglesa, especificamente após a decadência do Império Mugal (incluía quase todo o subcontinente indiano), no início da segunda metade do século XIX.

Na América Latina, a Revolução Francesa desencadeou uma série de lutas pela independência das colônias hispânicas, e no Brasil, a ascendência napoleônica foi o motivo para a transferência da Casa de Bragança para a colônia, que se tornou uma república em 1889, em pleno auge da Primeira Revolução Industrial.

Nesse período, no Brasil, as estradas de ferro começaram a ser construídas, possibilitando a expansão da cafeicultura como principal produto de exportação do país na época. As primeiras ferrovias conectavam o litoral ao interior, ligando a produção aos portos e possibilitando a transferência das "casas grandes" para as cidades. Muitos espaços urbanos foram tecnificados (ferrovias, iluminação pública, calçamento, saneamento) para receber a elite política nacional, como foi o caso da cidade de São Paulo (Monbeig, 1946).

Na Europa, as principais implicações foram percebidas quando houve a substituição da tração animal por máquinas a vapor. Estas passaram a ser incorporadas em navios e locomotivas, ocupando o lugar das tradicionais e caras aberturas de canais hidroviários, que haviam sido ampliados desde o fim do século XVIII de $2.500 \mathrm{~km}$, para $3.500 \mathrm{~km}$ em 1835; chegando a $4.000 \mathrm{~km}$ em 1890 (Niveau, 1969). Ainda que, somente no século $\mathrm{XX}$, os barcos a vela seriam definitivamente substituídos pela tecnologia a vapor, que passou a dominar os mares.

Outra nova tecnologia que se difundiu nesse período foi o telégrafo, que possibilitou a difusão da informação a longas distâncias. Nesse momento, as informações (e até mesmo, o comércio de dinheiro - pagamentos, trocas monetárias, entre outros), parte 
importante das comunicações, perderam sua tangibilidade, deixaram de acompanhar a velocidade e o percurso dos meios de transportes comuns, como o rodoviário, ferroviário, marítimo e outros. A velocidade e a distância para as trocas de informações e movimentações financeiras cresceram substancialmente em relação à mobilidade física das mercadorias e das pessoas, alterando significativamente a relação espaço/tempo.

As mudanças foram tão proeminentes, que o pai da Geografia na França, Paul Vidal de La Blache (1946:307), ao analisar a expansão das ferrovias de 1830 a 1938, relatou que:

O estado atual das comunicações faz surgir sob luz crua os efeitos do isolamento; pelo menos, este não parecia anomalia, uma espécie de infracção às condições gerais. Foram os progressos do comércio aos serviços de uma indústria exigente de matérias-primas, ávida de mercados, que aumentaram o afastamento, abrindo quase um abismo entre as regiões englobadas na rede mundial e aquelas que lhe escapam.

Já na América Latina, essa revolução logística, foi notada com mais veemência no final do século XIX, uma vez que o navio a vapor reduziu o custo e o tempo para cruzar o Oceano Atlântico. Esse meio de transporte fortaleceu o comércio mercantil com o principal centro do sistema econômico mundial, a Inglaterra.

Foram instaladas, no século XIX, as primeiras ferrovias na América do Sul. A saber, em 1848 na Guiana Inglesa (atual Guiana), em 1851 no Chile com a inauguração da linha ferroviária entre Calderón e Copiapó; em 1854 no Peru, conectando Lima a El Callao, em 1854 no Brasil conectando o Porto de Mauá a Fragoso no Rio de Janeiro, em 1857 na Argentina com a implantação de $9 \mathrm{~km}$ de ferrovias, que conectavam o centro de Buenos Aires até o bairro de Floresta (Almeida,1986).

Essas novas redes férreas, em sua maioria, foram projetadas no sentido litoral-interior, geralmente sobrepondo-se às antigas rotas de colonização, constituindo vias de penetração mais eficientes para drenar os recursos naturais das antigas colônias (Silveira, 2007). Ao avaliar o caso brasileiro, Pierre Monbeig (1946) apontou que as ferrovias por possuírem um traçado menos maleável, os pontos de parada eram dinâmicos, originando em algumas localidades cidades induzidas pela instalação da via. Uma rede urbana formava-se ao longo dos principais troncos e linhas ferroviárias.

\section{A criação do mercado doméstico e a integração dos territórios nacionais}

A revolução logística que iniciou no final do século XIX e parte do século XX permitiu uma elevação da velocidade das transformações técnicas e organizacionais, sobretudo, na Alemanha e nos Estados Unidos. Deste modo, a revolução logística, condicionou como ocorreu anteriormente, uma conflagração de caráter mais amplo, ou seja, a Segunda Revolução Industrial (Silveira, 2009).

Com o advento da eletricidade foi possível uma maior mobilidade das plantas industriais (processo iniciado com a utilização da máquina a vapor como força motriz) que deixavam de se localizar necessariamente próximas às quedas e corredeiras d'água e passavam a ser atraídas para as cidades (ganhos de escala e economias de aglomeração). Já o motor a combustão, no decorrer do século XX, passou a substituir o antigo motor a vapor em automóveis, barcos, navios e locomotivas. Mais tarde, o advento dos aviões permitiu a redução brusca do tempo de circulação. Já o telégrafo intercontinental (via cabos submarinos) liberou a troca de informação em tempo real, impulsionando da escala regional para a internacional a história das finanças (Silveira, 2009). 
Nesse momento, as relações comerciais e de poder em escala planetária ampliaram as relações imperialistas (fase expansionista dos impérios decadentes), decorrendo em uma corrida neocolonialista, pautada no expansionismo territorial, na busca de matérias-primas e mercados na África e Ásia. A respeito desse período, o economista inglês John A. Hobson, em 1902, destaca:

(...) no seu livro sobre o imperialismo os anos que vão de 1884 a 1900 como um período de intensa "expansão" (aumento territorial) dos principais estados Europeus. Segundo os seus cálculos, a Inglaterra adquiriu durante esse período 3.700.00o milhas quadradas com uma população de 57 milhões de habitantes; a França, 3.600.00o milhas quadradas com 36,5 milhões de habitantes; a Alemanha 1.000.000 milhas quadradas com 30 milhões de habitantes; Portugal, 800.000 milhas quadradas com 9 milhões de habitante. Em fins do século XIX, sobretudo a partir da década de 1880, todos os Estados capitalistas se esforçaram por adquirir colônias, o que constitui um facto universalmente conhecido da história da diplomacia e da política externa (Lenine, 1977:634).

Nas Américas ocorreu o rompimento do sistema colonial e da escravidão, entrementes, os países latino-americanos se mantiveram em posição de semicolônia (gravitando entorno das economias hegemônicas, mesmo que algumas já decadentes, como a Inglaterra), isto é, países independentes politicamente, porém estritamente dependentes do comércio, da indústria e do financiamento internacional. Contudo, o Brasil e o México passam a gravitar em torno dos Estados Unidos, fato que permitiu um processo de industrialização mais expressivo em comparação aos demais países da América Latina (Rangel, 1987).

Com a Primeira Guerra Mundial (1914-1918) houve a redução das pressões externas e a queda do comércio internacional. Tais acontecimentos, atrelados à onda nacionalista e às ambições da burguesia nacional, facilitaram a adoção de uma política pautada no desenvolvimentismo por parte dos países sul-americanos, com destaque para a Argentina, o Brasil, a Venezuela e o Chile (Furtado, 1986).

Esses países começaram a utilizar, enquanto estratégia de crescimento econômico, a substituição de produtos industrializados importados por produtos de procedência nacional (substituições escalonadas de importações, como respostas às crises cíclicas emanadas do centro do sistema capitalista), resguardando e buscando a ampliação dos seus mercados consumidores, que ainda eram incipientes para as indústrias nascentes (da produção natural até a industrial) (Rangel, 1993).

Nesse momento, a ocupação territorial e, por imediato, a base infraestrutural sul-americana tenderam a se tornar densas nas antigas áreas ocupadas pelas rotas de colonização que, em muitos casos, tiveram sua atratividade reforçada pela instalação das ferrovias. A concentração das redes de transporte e comunicação em certas localidades atraiu mais inversões, resultando em uma contínua tecnificação de terminadas parcelas do território.

Mas, a burguesia nacional nascente, com a necessidade crescente de consolidar/ampliar o mercado interno, exigiu que os Estados-Nação também passassem a destinar uma grande soma de investimentos para realizar a integração dos seus respectivos territórios, por meio da expansão das rodovias. Nesse sentido, podemos afirmar que as estradas de ferro serviram muito mais para a economia agroexportadora, enquanto que as rodovias convieram mais a industrialização via substituições de importações, demonstrando-se mais eficiente para a rápida integração dos territórios nacionais, conectando os múltiplos arquipélagos geoeconômico e, suprindo as necessidades do capitalismo industrial nascente. 
A preferência do governo brasileiro de integrar o território nacional por rodovias foi similar a muitos países da região. Ignácio Rangel (1987) afirma que essa escolha não apresentava nada de inconsequente, ao contrário, era estratégica. Tal opção possibilitava realizar investimentos gradativos, uma vez que se podia utilizar a rodovia antes da mesma ser finalizada, ou seja, antes de receber pavimentação, guias, sinalização e todas as infraestruturas acessórias e indispensáveis (Rangel, 1987).

A flexibilidade das rodovias era notória. Bastava o Estado abrir uma clareira entre dois pontos que a ocupação do território era especialmente realizada com capital privado. O transportador adquiria o caminhão, o ônibus e os clientes arcavam com os custos de transportes, numa relação vívida entre o público e o privado. Ao longo das precárias estradas instalaram-se postos de combustíveis, hospedagens, restaurantes e serviços diversos para caminhoneiros e todos os que necessitassem de um ponto de paragem.

Deste modo, gerava-se uma centralidade, um processo de urbanização e mais um nó da rede urbana. A rodovia reconfigurou a rede urbana sul-americana, que se tornou mais integrada, reforçando antigas centralidades, desestruturando outras, e até mesmo criando novas. Afinal, a atual estrutura da rede urbana é o reflexo de formas do passado, embasadas nas forças produtivas e nas relações de produção vigentes, acumuladas historicamente (estruturas e processos). Os atuais traçados e nós da rede de transportes são, na maioria dos casos, expressões do passado, uma herança territorial.

Além do mais, com os países integrados pelo modal rodoviário foi possível incentivar o desenvolvimento da indústria automobilista. Conforme apontavam estudos da época, essa indústria apresentava um grande potencial para o desenvolvimento de um parque industrial eficiente, que mobilizava uma vasta cadeia produtiva. A tática foi adotada notadamente pelo Brasil e Argentina que, por meio das montadoras estrangeiras, desenvolveram um parque industrial importante de autopeças, com alto índice de conteúdo nacional para países periféricos.

Sendo assim, na primeira metade do século XX, os países da região deram início à construção de sua malha rodoviária nacional. As estradas e rodovias, geralmente foram construídas próximas às antigas linhas ferroviárias (realizando concorrência com as mesmas), em outros casos acompanharam os cursos hidrográficos e caminhos primitivos (caminhos indígenas, de tropas e estradas carroçáveis). A rede de rodovias possibilitou a integração das cidades, dos estados e das províncias, que embora fossem partes do mesmo país apresentavam poucas interações espaciais entre si. Ademais, as rodovias, ainda que muitas vezes descontínuas, adentraram o interior das nações, alcançando regiões ainda descobertas pelas ondas de modernizações, emanadas do centro do sistema capitalista.

Após a Segunda Guerra Mundial, mesmo com a Guerra Fria em processo, ocorreu a retomada do comércio internacional pelas economias centrais. Tal ação, atrelada às decisões resultantes da Conferência de Bretton Woods, que estabeleceram os parâmetros que deveriam seguir as relações comerciais, implicou num movimento de liberalização do comércio exterior e dos movimentos de capitais, impondo a queda da participação da América Latina no comércio mundial de 14\% em 1945, para 5\% em 1970 (ALADI, 1983), mesmo durante o período de expansão da economia capitalista.

Em contraposição à retração da participação da região no comércio internacional, muitas economias nacionais continuaram a política de substituição de importações e constituíram um destacado complexo industrial. Fato só possível com a rápida e ampla integração territorial dos arquipélagos geoeconômicos nacionais (mercados de matérias-primas, produtores de manufaturas e consumidores) mediante a expansão das redes rodoviárias (Silveira, 2007). 
No ano de 1949, o economista argentino Raúl Prebisch, publicou um informe, que chamava atenção dos governantes latinos as limitações de uma industrialização restrita aos mercados nacionais (Furtado, 1986). Nos anos seguintes, planejadores e políticos passaram a perceber na integração regional, uma possibilidade para criação de complementaridade entre os parques industriais existentes e de ampliação do mercado consumidor potencial, que possibilitaria às indústrias aumentarem a produção nacional e, por conseguinte, expandirem a criação de vagas de empregos (Furtado, 1986).

Os países latinos respondiam, em 1966, por apenas 8,8\% das exportações e 11,9\% das importações, enquanto os Estados Unidos e o Canadá eram responsáveis por 35,5\% das exportações e $46,9 \%$ das importações. Por outro lado, havia uma baixa complementaridade entre as economias regionais latino-americanas, cuja ampliação tornou-se estratégica. Esse ideário integracionista dos territórios latino-americanos é evidente desde os tempos das lutas por independência da Espanha e uma tradição que perfaz a visão bolivariana (na qual o Brasil foi/é muito pouco adepto).

Ora, a América Latina passava por um momento de crescimento desigual e tardio para dentro. Enquanto os Estados Unidos da América, Canadá e alguns países da Europa experimentavam o crescimento para fora, via a implantação de multinacionais, especialmente, pois já haviam passado por forte período de financeirização e industrialização.

Nessa conjuntura, objetivando ampliar o comércio regional latino-americano, diversas iniciativas foram realizadas visando equalizar as questões normativas e tributárias entre os países. A integração física da região, nunca foi considerada prioridade, porém muitas rodovias e pontes foram construídas por meio de tradados bilaterais, ademais os dirigentes nacionais apoiaram a realização de diversos estudos visando avaliar e estabelecer prognósticos referentes às condições das infraestruturas de transportes e comunicações no continente.

Deste modo, a partir segunda metade do século XX, diversas organizações internacionais, destinadas a impulsionar a integração regional, publicaram estudos dedicados a promoção da integração física entre os países da região, como: a ALALC (Associação Latino-americana de Libre Comércio), a ALADI (Associação Latino-americana de Integração), a CEPAL (Comissão Econômica para a América Latina e o Caribe) o Instituto para a Integração da América Latina e o Caribe (INTAL), entre outros.

Com o findar da Guerra Fria, no início da década de 1990, os Estados Unidos afirmouse enquanto uma superpotência de um mundo unipolar. Sua hegemonia imperialista, já latente no decorrer do século XX, sucedeu no que François Chesnais (1996) chamou de mundialização do capital (Chesnais, 1996) e, temporalmente depois, Ellen Wood (2014), chamou de "império do Capital".

Isto posto, as empresas multinacionais passam à categoria de transnacionais respaldadas pelos Estados nacionais, a manipulação do dólar, a coerção econômica e a ameaça (supremacia) militar (forças extra-econômicas, ações policiais localizadas e cirúrgicas) passaram a fazer parte de um sistema econômico repleto de "Estados múltiplos". ${ }^{\text {"Uma }}$ visão diferente da que possui Michael Porter (1986), para o qual as empresas multinacionais se tornaram globais, por meio da internacionalização da marca do produto via crescimento da firma, mediante estratégias competitivas e de aproveitamento das lógicas políticas e econômicas decorrentes da liberalização do comércio internacional. Uma vez que, para alcançar uma escala global a presença do Estado nacional tem que ser mais intensa, até mesmo, por meio dos enfretamentos geopolíticos.

Precisamente, o que se apresenta para a segunda metade do século XX é o denominado por Wood (2014) de "império do capital", onde o império (Estados Unidos) opera o
6. "O mundo de hoje é mais do que nunca um mundo de Estadosnação. A forma política da globalização não é um Estado global, ou uma soberania global. A falta de correspondência entre a economia global e os Estados nacionais também não representa simplesmente algum tipo de atraso no desenvolvimento político. A própria essência da globalização é uma economia global administrada por um sistema de Estados múltiplos e soberanias locais, estruturada numa relação complexa de dominação e subordinação" (Wood, 2014:108). 
máximo possível por meio de imperativos econômicos, substituindo o domínio colonial direto. Ora, um projeto imperialista em que "a bandeira fica em casa e o dólar vai a onde quer que se deseje, devidamente respaldado pelo aparato armamentista" (ParentI, 1995 apud Betti, 2003:35).

Ainda, nesse mesmo período, ocorreu a financeirização da economia. Esse componente exigiu uma maior produção da mais-valia e a expropriação na periferia do sistema capitalista. A medida que as empresas passaram a fragmentar suas cadeias produtivas em busca de vantagens comparativas que o espaço pudesse oferecer, como menores custos de produção e circulação. Com isso, as empresas também passaram a instalar filiais na periferia à procura de maiores taxas de lucro, influindo na circulação de mercadorias, $o$ que afetou a organização do espaço. A lógica de concentração e centralização do capital não foi extinta, mas seus métodos de disposição foram alterados, nos quais os sistemas de transportes, comunicações e logística tornaram-se mais decisivos.

Tomam-se como exemplos os casos examinados de desconcentração e reconcentração da produção e centralização da gestão das corporações pelo território brasileiro (Lencioni, 1994; Pochmann, 2001). As novas dinâmicas de localização buscam, em grande medida, aproximar-se dos principais "eixos de desenvolvimento", em especial, ao longo das infraestruturas mais tecnificadas, isto é, as infovias (Sposito, 2015). Para essa dinâmica econômica global, que envolve novas cadeias globais de produção e distribuição, foi determinante a ampliação (e redução de custos) dos sistemas de transportes, armazenamento e logística, além de padronizações de suas normas e tributações em escala global (Silveira, 2009). Logo, gesta-se mais uma revolução logística que, especialmente, tem como foco a logística corporativa (das empresas) e a logística de Estado. A primeira tem como destaque as inovações organizacionais e a segunda à modernização das infraestruturas de transportes, auferindo ambas maior fluidez $\mathrm{e}$ competitividade territorial.

\section{A América do Sul, um continente em modernização e com padrões secularmente persistes}

As inovações, típicas do fim do século XX e início do século XXI, no setor de telecomunicações e informática (telemática) possibilitaram que as corporações conquistassem novos mercados de produção e consumo, ação facilitada pela diminuição dos custos de circulação do capital. Afinal, como caracterizou o economista argentino Aldo Ferrer,

\section{(...) nunca antes, en efecto, existieron redes de transmisión y procesamiento de datos en tiempo real de la magnitud y con los ínfimos costos actuales. Tampoco existió en el pasado un mercado financiero de semejante escala, en el que predominaran los movimientos de capitales de corto plazo (Ferrer, 2002:15).}

Além da telemática, houve a intensa ampliação das redes de fibra óptica e das comunicações por satélites, surgiram as infovias (vias altamente tecnificadas para a circulação de mercadorias e informações), ampliaram-se as autoestradas (freeways e autobans), os trens de média e alta velocidade, a difusão da conteinerização, da modernização portuária e aeroportuária, dos navios conteineiros, entre outros feitos (Silveira, 2009). Todos esses aspectos qualificam-se para a mais recente revolução logística, caracterizada por um período inovador, mas onde as invenções básicas são menos representativas do que as de processos e incrementais. Mesmo assim, o setor de transportes e comunicações se modernizaram suficientemente para contribuírem significativamente com a diminuição dos custos de circulação e para a ampliação dos mercados. Porém, essas modernizações estão mais atreladas ao desenvolvimento das inovações que são 
aperfeiçoamentos das invenções da Segunda Revolução Industrial. O momento atual também é caracterizado por uma inovação organizacional embasada fortemente nas estratégias logísticas. Mesmo assim, havendo disponibilidade tecnológica, a América Latina e, mais especificamente, a América do Sul, carecem de financiamentos e investimentos mais do que novas tecnologias para aumentar a fluidez e a competitividade em seus territórios.

Na economia, a expansão da dívida latino-americana, na década de 1980, representou para os países da região, em apenas três anos (1981-1983), um dispêndio de 81,7 bilhões de dólares para quitá-la, quase o dobro do que os países haviam pago na década de 1970 (Gonçalves e Pomar, 2002), resultando no direcionamento dos países da região para a resolução do saneamento de suas finanças. A implicação foi a gradativa redução dos investimentos em infraestruturas em relação ao Produto Interno Bruto (PIB), de $0,8 \%$ no período de $1980-1985$, para $0,4 \%$ no período de 1996-2001 (Santiago, 2011). Os investimentos estatais, notadamente em serviços públicos, passaram a ser compreendidos enquanto despesas que deveriam ser saneadas, ao passo que as privatizações e as concessões, tornaram-se as alternativas mais aceitas para reequilibrar as contas públicas.

Nessa lógica, na América do Sul, grande parte das ferrovias foram concedidas, e muitos trechos considerados antieconômicos foram desativados (Silveira, 2007). Isto posto, prevaleceram em funcionamento somente os trechos lucrativos associados às exportações de commodities (corredores agroexportadores e de minérios). Apesar de mais de um século de existência, as ferrovias continuaram designadas a integrar as zonas produtoras aos portos, assegurando quase que exclusivamente as demandas do comércio internacional (interior-litoral).

No setor aéreo, García e Córdoba Ordónez (2013) identificaram o surgimento de novos aeroportos, mas o que prevaleceu foi a modernização de aeroportos nos maiores centros urbanos latino-americanos. Todavia, a aviação regional cresceu consideravelmente, especificamente no Brasil. A malha rodoviária dos países tornou-se mais densa e complexa, já os trechos com maiores fluxos econômicos (insumo-produto) foram concedidos à iniciativa privada (inclusive para grupos estrangeiros), gerando uma série de outros problemas, gerados pela falta de investimentos e altos lucros, encarecendo os custos de circulação. Apesar dos avanços, os registros ligados aos investimentos em infraestruturas de transportes estão mais relacionados a ruptura dos nós de estrangulamentos do que a uma expansão efetiva da rede de transportes.

A integração física regional ganhou um novo impulso através da criação da IIRSA (Iniciativa para a Integração da Infraestrutura Regional Sul-Americana), no ano 2000. Esse organismo, diferente dos demais de integração regional, já nasceu com propósito de impulsionar a coesão infraestrutural regional, por meio da construção, ampliação e modernização das infraestruturas de comunicação e transportes sul-americanas. Já com a institucionalização da UNASUL (União das Nações Sul-Americanas), a IIRSA foi incorporada como foro técnico de infraestrutura do recém-criado Conselho Sul-Americano de Infraestrutura e Planejamento (COSIPLAN), no ano de 2011 (Souza, 2015).

Sobre a responsabilidade da IIRSA e do Cosiplan foi elaborado um dos maiores portfólios de obras do mundo. A saber, o número de obras cresceu de 335 a 562, no biênio de 20032004 até o ano de 2017; já para o mesmo período os investimentos estimados aumentaram em um contínuo de US\$37.425 milhões, para US\$198.901 milhões (COSIPLAN, 2017). Sendo que, muitas das obras foram direcionadas para as regiões correspondentes ao bloco Mercosul e Andino, visando atender as demandas coorporativas por fluidez territorial dessas regiões, mas também desconcentrando investimentos para criação e modernização de conexões destinadas a áreas até então periféricas (Souza, 2015). 
A questão referente às redes de comunicação regionais ganhou foco, a partir do ano de 2013, devido a denúncia realizada por Edward Snowden ao jornal The Guardian, que possibilitou aos governantes e a opinião pública sul-americana tomarem conhecimento das práticas de espionagem dos EUA. Visto que, a Agência de Segurança Nacional Americana, estava utilizando o software XKeyscore, para obter acesso ilegal a ligações telefônicas, além de informações de usuários da internet, em diversos países da região, assim como na Alemanha, na França e na Itália (Souza e Silveira, 2014).

Tal delação resultou no direcionamento da atenção do poder público para a problemática das novas redes de comunicação no território, especialmente, das infraestruturas de fibra óptica. Uma vez que, a instalação dos primeiros cabos submarinos de fibra óptica nos países da América Latina, a partir da década de 1980, estabeleceu uma morfologia, pautada na reprodução da lógica: centro-periferia (Zibechi, 2012).

Nesse sentido, no ano de 2013 os EUA intermediaram aproximadamente $80 \%$ dos fluxos de informação da América Latina, condição limitadora para interações comunicacionais entre os países do continente. Justamente, porque esse longo percurso reduziu a velocidade nos fluxos de dados e acarretou, conforme relatado pelo Ministro da Indústria e Energia do Uruguai, Roberto Kreimerman, na ampliação dos custos das conexões entre 30\% e 50\% (Zibechi, 2017). Essa situação colocou as redes de fibras ópticas como uma questão de soberania aos países do continente, haja vista que:

Un mail enviado entre dos ciudades limítrofes de Brasil y Perú, por ejemplo entre Rio Branco, capital de Acre, y Puerto Maldonado, va hasta Brasilia, sale por Fortaleza en cable submarino, ingresa a Estados Unidos por Miami, llega a California para descender por el Pacífico hasta Lima y seguir viaje hasta Puerto Maldonado. Un recorrido de 8.000 kilómetros para cubrir una distancia de sólo 300 kilómetros (Zibechi, 2017).

Os argumentos apontados colaboram para evidenciarmos como a rede de transportes e comunicação sul-americana, após séculos de inserção periférica da região ao mercado mundial continuam orientadas, em grande parte, para o exterior. Tendência que foi acentuada com a consolidação dos Estados Unidos como "império do capital", em interação com os demais Estados associados à sua lógica imperialista (Wood, 2014).

Quer dizer que, "[...] o Estado territorial se tornou muito mais, e não menos, essencial para a organização dos circuitos econômicos, por meio de relações internacionais" (Wood, 2014:11). Pois, embora as relações comerciais sejam desiguais, a maioria dos países e suas regiões dependem, cada vez mais, de balanças comerciais favoráveis para financiar suas economias. Sendo assim, não surpreende que os territórios intranacionais criem relações internacionais sem necessariamente a intermediação direta do Estado-nação. Há, com isso, uma reciprocidade partindo das estruturas do passado para as do presente, obviamente com a mudança de certas funções ao longo dos processos históricos.

Herdados do passado pré-colombiano, muitos desses fixos mantêm ainda hoje estreita correspondência com aquele legado, como atestam indubitavelmente as altas densidades populacionais das mesetas mesoamericanas, do altiplano andino, e da planície costeira brasileira (Martin, 2010:43).

Como afirmava Shanahan (1954), após 300 anos de período colonial a ocupação territorial sul-americana foi evidentemente periférica, característica que se conservou no decorrer dos séculos. No entendimento de Beyer (1969), a América do Sul é um continente em modernização, mas que cristalizou um padrão de ocupação, que mesmo ao findar a colonização, parece subsistir até mesmo ao advento das ferrovias e das rodovias. Com algumas exceções, em conformidade com Fernández 
(2011), pode-se afirmar que a América do Sul possui uma ocupação territorial basicamente em forma de "cáscara de huevo", isto é, densificada na porção litorânea do continente e que ao adentrar mais de $100 \mathrm{~km}$ da costa torna-se gradativamente mais rarefeita.

Essa metáfora, ainda que simplória, aponta para uma concentração populacional, econômica, das redes e dos fluxos que secularmente persiste. A modernização não atinge todos os espaços e, por isso, deixa resquícios de relações de produção e de trabalho arcaicas. De tal modo, evidencia-se formações socioespaciais diversas e, por conseguinte, com distintos estágios de desenvolvimento dos seus sistemas de transportes, armazenamento e comunicações. Mesmo que nas últimas décadas tenha ocorrido movimentos expressivos de interiorização da modernização, em partes do Brasil (região centro-oeste) e, em porções da Argentina (região pampeana), assim como em outros países da região, o que ainda prevalece é um desenvolvimento amplamente desigual e conectado aos interesses do centro do sistema capitalista.

\section{Considerações finais}

O continente sul-americano relacionou-se de forma periférica com o capitalismo mundial. Ainda que a história do continente não seja reflexo exclusivo das expansões terrestres e marítimas europeias, realizadas no século XV, deve-se considerar que do ponto de vista das relações de produção e de trabalho esse episódio resultou para região, em apenas 500 anos, uma evolução multifacetada do capitalismo primitivo ao capitalismo financeiro, por meio de ciclos de modernização das redes no espaço geográfico. O novo e o velho, a continuidade e as descontinuidades das forças produtivas e das relações de produção fazem parte constante da nossa história e são amplamente evidentes.

No decorrer da revolução logística, por objeto das expansões marítimas, o império colonial espanhol alcançou a pacificação de quase todos os seus territórios (com exceção dos pampas). Para tanto, utilizou-se de antigos e novos caminhos, mas, sobretudo reforçou os usos das redes já existentes que realizavam a ligação entre as jazidas de metais preciosos e o litoral. Já na colônia portuguesa, destacou-se a ocupação territorial das proximidades do litoral, seguida de uma ocupação que adentrou a fachada litorânea e atlântica, com a criação de redes, cuja função foi quase exclusivamente possibilitar o escoamento das mercadorias demandadas pelas metrópoles.

Na revolução logística, do final do século XVIII e início do século XIX, houve uma modernização das redes de transportes e comunicações embasadas no desenvolvimento das estradas de ferro e posteriormente nos navios a vapor. Mas elas conectaram mais os centros produtores de matérias-primas aos portos, com o objetivo de ampliar as relações imperialistas. Episódio que expressa a abertura dos portos brasileiros, em 1808, às nações estrangeiras, especialmente, à Inglaterra. Por outro lado, na região do Cone Sul, especialmente entre Brasil, Argentina, Uruguai e Chile, iniciou-se gradativamente a construção das primeiras infraestruturas ferroviárias entre os países.

Com a revolução logística, do final do século XIX e todo século XX, grande parte das nações dedicaram-se ao rodoviarismo, integrando por meio dessa nova rede infraestrutural porções até então periféricas dos seus territórios nacionais. Ademais, alguns países realizaram importantes acordos bilaterais, que resultaram na construção de notáveis obras de integração entre suas fronteiras, porém, algumas foram subaproveitadas, como a Ponte Binacional Franco-Brasileira (entre Amapá/Brasil e o Departamento Francês da Guiana), que possibilitaria maior integração com a União Européia, Venezuela, 
Colômbia e Ilhas do Caribe. A expansão das infraestruturas para essas novas áreas estabeleceu condições gerais de produção para o alargamento da atividade produtiva às novas regiões, ampliando, por mais que de forma ainda tímida, os respectivos mercados domésticos de cada país.

Mediante a revolução logística, do fim do século XXI, as novas tecnologias comunicacionais permitiram que muitas cidades sul-americanas se tornassem importantes centros de serviços, com a concentração da gestão das empresas e a dispersão do chão de fábrica das mesmas para áreas mais longínquas (horizontalizou-se as cadeias produtivas), resultando em uma crescente desconcentração produtiva seletiva e uma centralização da gestão corporativa.

Por sua vez, os novos espaços que concentraram e centralizaram essas atividades possuem um componente fundamental e comum ao meio técnico-científico e comunicacional, ou seja, uma tecnificação assegurada pelas infovias. Por outro lado, com o processo de integração dos territórios nacionais, os países sul-americanos, agora conjuntamente, voltaram a planejar e executar obras de integração física supranacionais, cuja prioridade, no decorrer das últimas décadas, oscilariam conforme as trocas de dirigentes políticos na região, suas prioridades e ideologias.

No atual estágio de desenvolvimento dos transportes e comunicações, as barreiras físicas, como é o caso da Cordilheira dos Andes, na América do Sul, tornam-se impasses possíveis de serem equacionados com reduzidos impactos socioambientais. Vale lembrar que, em outros países de topografia acidentada, como Japão, Suíça e México, solucionaram muitos dos seus problemas de transporte com os padrões técnicos disponíveis, isto é, sem a necessidade de gestar novas tecnologias. A China é um grande exemplo, pois conseguiu expandir tanto a circulação interna quanto com o exterior sem nenhuma tecnologia revolucionária. Bastaram investimentos em sistemas de engenharia e aperfeiçoamentos técnicos e organizacionais.

O estabelecimento de uma estratégia nacional e regional de desenvolvimento torna-se fundamental para encaminhar a contínua modernização das redes de transporte na região, visando a consolidação de uma matriz de transportes mais equilibrada e com uma distribuição das infraestruturas mais equitativa pelo território. Para tanto, o planejamento deve-se pautar tanto na conciliação dos múltiplos interesses que demandam por maior fluidez territorial quanto à capacidade dos países em financiar os investimentos demandados. Sumariamente, a ampliação da coesão e da fluidez do território sul-americano perpassa por uma conciliação regional e depois por uma forte resistência aos interesses imperialistas que procuram desarticular política e economicamente os blocos regionais sul-americanos.

\section{Agradecimentos}

O presente trabalho foi realizado com apoio do Conselho Nacional de Desenvolvimento Científico e Tecnológico (CAPES). 


\section{Q Bibliografía}

» Almeida, J. L. do O’ de. (1986). Os transportes na América Latina. Rio de Janeiro: Escola de Comando e Estado-Maior do Exército.

" Anderson, A. (1990). Les quatre révolutions logistiques. UHT 2001 (Urbanisme et techologies de l'habitat). Paris: Ministère de l'Équipement du Logement, dês Transports et de la Mer, (15), mai,1-14.

»Asociación Latinoamericana De Integración - ALADI. (1983). Evolución y estructura del intercambio comercial de los países que integran la ALADI, 19521980. Montevideo, março (Estudo 5).

»Betti, M. S. (2003). Marx Tawain: uma redescoberta oportuna. In: TAWAIN, M.; Betti, M.S. (orgs.). Patriotas e traidores: antiimperialismo, política e crítica social. São Paulo: Perseu Abramo.

"Beyer, G. H. (1969). The urban explosion in Latin America: a continent in process of modernization. Rio de Janeiro: Victor Publicações.

》 Blache, V. de La. (1946). Princípios de geografia humana. Lisboa: Cosmos.

»Dobb, M. (1983). A evolução do capitalismo. Rio de Janeiro: Editora Jorge Zahar.

》Chesnais, F. (1996). Mundialização do capital. São Paulo: Xamã.

»Cholley, A. (1964). Observações sobre alguns pontos de vistas geográficos. Boletim Geográfico. Rio de Janeiro 22 (179), 139-145.

»Christaller, W. (1966). Central Places in Southern Germany. London: PrenticeHall. Traduzido por W/ Baskin.

"Clydesdale, G. (2012). Cargas: como os negócios mudaram o mundo. Rio de Janeiro: Record.

»Corrêa, D. S. (2006). Os rios na formação territorial do Brasil: considerações sobre a historiografia paulista. Encontro da ANPPAS 3, Brasília, DF.

»Corrêa, R. L. (1997). Interações espaciais. In: Castro, I. E. de, et. al. (org.) Explorações geográficas. Rio de Janeiro; Bertrand Brasil, 279-318.

" Cosiplan. (2017). Cartera de Proyectos 2017. UNASUR / IIRSA: Buenos Aires, Argentina.

"Derruau, M. (1969). Tratado de Geografía Humana. Barcelona: Editorial Vicensvives.

»Dominguez Compañy, F. (1978). La vida en las pequeñas ciudades hispanoamericanas de la conquista. Madrid: Cultura Hispánica del Centro Iberoamericano de cooperación, 15-44.

"Fernández, W. N. (2011). IIRSA: desafíos y oportunidades de un megaproyecto controversial. In: Mateo, M. C.; Mellado, N. B. (org.). Los cambios en la infraestructura regional y sus impactos ambientales en clave de mejorar la governabilidad en el Mercosur. Córdoba (Argentina): Lerner, 129-150.

»Ferrer, A. (2002). De Cristóbal colón a internet: América Latina y la Globalización. Buenos Aires: Fondo de Cultura Económica.

» Furtado, C. (1986). A economia Latino-Americana: formação histórica e problemas contemporâneos. São Paulo: Ed. Nacional. 
» García, C. G.; Córdoba Ordónez, J. A. (2013). Sistemas urbanos en América Latina: Roles y advenimientos de nuevos centros desde la perspectiva del transporte aéreo. In: Anales de Geografía de la Universidad Complutense, 33, (2), 9-17.

" Gonçalves, R.; Pomar, V. (2002). A armadilha da dívida. São Paulo: Ed. Fundação Perseu Abramo.

" Grimm, F. (2010). Pensando a Urbanização na América Latina durante as décadas de 1960-1970 a partir da contribuição teórica do geógrafo Milton Santos. In: ARROYO, M.; ZUSMAN, P. (org.). Argentina e Brasil: possibilidades e obstáculos no processo de integração territorial. São Paulo / Buenos Aires: Ed. Humanitas/ Facultad de filosofía y letras, 163-194.

» Haggett, P. (1965). Locational analysis in Human Geography. Londres: Edward Arnold.

" Harvey, D. (2006). A produção capitalista do espaço. São Paulo: Annablume.

»Helferich, G. (2005). O cosmos de Humboldt: Alexander Von Humboldt e a viagem à América Latina que mudou a forma como vemos o mundo. Rio de Janeiro: Objetiva.

» Keeling, D. J. (1993). Transport and Regional Development in Argentina: Structural Deficiencies and Patterns of Network Evolution. Conference of Latin Americanist Geographers. Texas: University of Texas Press 19 (1), 25-34.

»Lencioni, S. (1994). Reestruturação urbano-industrial no Estado de São Paulo: a região da metrópole desconcentrada. Espaço \& Debates. São Paulo, NERU, (38), 54-61.

"Lénine, V. I. (1977). O imperialismo, fase superior do capitalismo. In: LÉNINE. V. I: Obras escolhidas. Tomo I. Lisboa: Ed. Avante, 575-671.

»Losurdo, D. (2006). Liberalismo. Entre civilização e barbárie. São Paulo: Anita Garibaldi.

" Mamigonian, A. (2000). Marxismo e globalização: as origens da internacionalização mundial. In: SOUZA, À. J. de et al. (org.). Milton SantosCidadania e Globalização. Bauru (Brasil): Associação dos Geógrafos Brasileiros, 95-100.

"Martin, A. R. (2010). Sopa de letrinhas: ALBA, ALCA, MERCOSUL, USAUL, CAN... Para onde vai a integração latino-americana? In: Arroyo, M.; Zusman, P. (org.). Argentina e Brasil: possibilidades e obstáculos no processo de integração territorial. São Paulo/Buenos Aires: Ed. Humanitas/Facultad de filosofia y letras, 37-58.

» Marx, K. (1978). O domínio britânico na Índia. In: Marx, K.; Engels, F. Sobre o colonialismo. Volume I. Lisboa, Editorial Estampa.

»Marx, K. (2005). O capital: crítica da economia política. Rio de Janeiro: Civilização Brasileira, 136-160. (Livro II).

» Monbeig, P. (1946). Estudo monográfico duma estrada de ferro. In: Boletim Geográfico: Rio de Janeiro 4 (45), 1147-1150.

"Niveau, M. (1969). História dos fatos econômicos contemporâneos. São Paulo: Difel.

» Novack, G. (1988). A Lei do Desenvolvimento Desigual e Combinado da Sociedade. São Paulo: Rabisco. 
Pendle, G. (1963). História da América Latina. Lisboa: Editora ULISSEIA.

» Pochmann, M. (2001). A década dos mitos: o novo modelo econômico e a crise do trabalho no Brasil. São Paulo: Contexto.

»Porter, M. (1986). Estratégias competitivas: técnicas para a análise da indústria e da concorrência. Rio de Janeiro: Campus.

» Raffestin, C. (1993). Por uma geografia do poder. São Paulo: Ática.

» Rangel, I. (1985). Intermediação financeira e crise. Revista Ensaios. Porto Alegre, 57-64.

»Rangel, I. (1987). Ferrovia versus rodovia. Revista Ferroviária. São Paulo.

»Rangel, I. (1993). 500 anos de desenvolvimento da América e do Brasil. Revista Geosul. Florianópolis (15), 7-12.

» Ribeiro, D. (2010). A América Latina existe? Rio de Janeiro, Fundação Darcy Ribeiro; Brasília, Ed. UNB.

"Sánchez, L. A. (1969). O crescimento urbano e a herança latino-americana. In: Beyer, G. H. The urban explosion in Latin America: a continent in process of modernization. Rio de Janeiro: Victor Publicações, 17-34.

» Santiago, P. B. (2011). Infraestrutura: experiência na América Latina. Brasília; CEPAL-IPEA. (Texto para Discussão CEPAL-IPEA, 35).

» Santos, Milton. (1982). Ensaios sobre a urbanização Latino-Americana. São Paulo: Hucitec.

» Santos, M. (1994). Técnica, espaço, tempo. São Paulo: Hucitec.

"Shanahan, E. W. (1954). América del Sur: Geografía económica y regional con un capítulo histórico. Barcelona: Ediciones Omega.

"Silveira, M. R. (2007). Estradas de ferro do Brasil: das primeiras construções às parcerias público-privadas. Rio de Janeiro: Interciência,

» Silveira, M. R. (2009). As cinco revoluções e evoluções logísticas: impactos sobre o território brasileiro. In: Silveira, M. R.; Lamoso, L. P.; Mourão, P. F. C. (orgs.). Questões nacionais e regionais do território brasileiro. São Paulo: Expressão Popular, 13-42.

» Silveira, M.; Cocco, R. G. (2010). Interações espaciais, transporte público e estruturação do espaço urbano. Revista Brasileira de Estudos Urbanos e Regionais 12 (1), 63-81. DOI: http://dx.doi.org/10.22296/2317-1529.2010v12n1p63.

» Silveira, M. R. (2011). Circulação, transportes e logística: bases para acumulação capitalista e a expansão geográfica do capital. In: Silveira, M. R. (org.) Circulação, transportes e logística no Estado de São Paulo. Curitiba/PR: Editora Appris, 21-68.

"Souza, V. H. P. de; Silveira, M. R. (2014). América Latina: cinco séculos em busca da integração. Revista Formação 1 42-71.

»Souza, V. H. P. de (2015). Integração territorial no Mercosul: o caso da IIRSA/ COSIPLAN. In: Sociedade \& Natureza. Uberlândia 27 (1), 21-36. DOI: http:// dx.doi.org/10.1590/1982-451320150102.

» Sposito, E. S. (2015). Rede urbana e eixos de desenvolvimento: dinâmica territorial e localização da indústria e do emprego no Estado de São Paulo. In: SPOSITO, E. S. (org.). O novo mapa da indústria no início do século XXI. Diferentes paradigmas para a leitura das dinâmicas territoriais no Estado de São Paulo. São Paulo: Editora UNESP, 369-404. 
» Ullman, E. (1972). Geography as spatial interaction. In: HURST, M. E. (org.). Transportation Geography. Londres: Macgraw Hill, 29-39.

》Wood, E. M. (2014). O império do Capital. São Paulo: Boitempo.

"Zibechi, R. (2012). O Brasil potencia: entre la integración regional y un nuevo imperialismo. Bogotá: Ediciones desde abajo.

"Zibechi, R. (2017). Internet: se profundiza la dependencia latinoamericana de EEUU. In: NODAL - Noticias de América Latina y el Caribe. Disponível em< https:// www.nodal.am/2017/12/internet-se-profundiza-la-dependencia-latinoamericanaeeuu-raul-zibechil.>. Acessado em 23 de agosto de 2018.

\section{Vitor Hélio Pereira de Souza / vitorgedri@hotmail.com}

Licenciado e Mestre em Geografia pela Universidade Estadual Paulista (UNESP), Doutor em Geografia pela Universidade Federal de Santa Catarina (UFSC). Pesquisador do Grupo de Estudos em Desenvolvimento Regional e Infraestruturas (GEDRI). Especialista em estudos sobre Integração Regional e Políticas de Transportes Regionais.

\section{Márcio Rogério Silveira / marcio.gedri@gmail.com}

Licenciado em Geografia pela Universidade do Estado de Santa Catarina (UDESC) e doutor em Geografia pela Universidade Estadual Paulista (UNESP). Professor do Departamento de Geociências e do Programa de Pós-Graduação em Geografia da UFSC. Pesquisador e bolsista do Conselho Nacional de Desenvolvimento Científico e Tecnológico (CNPq) e pós-doutorando no Instituto de Geociências da Universidade Estadual de Campinas (Unicamp). Especialista em estudos sobre transportes e logística. 